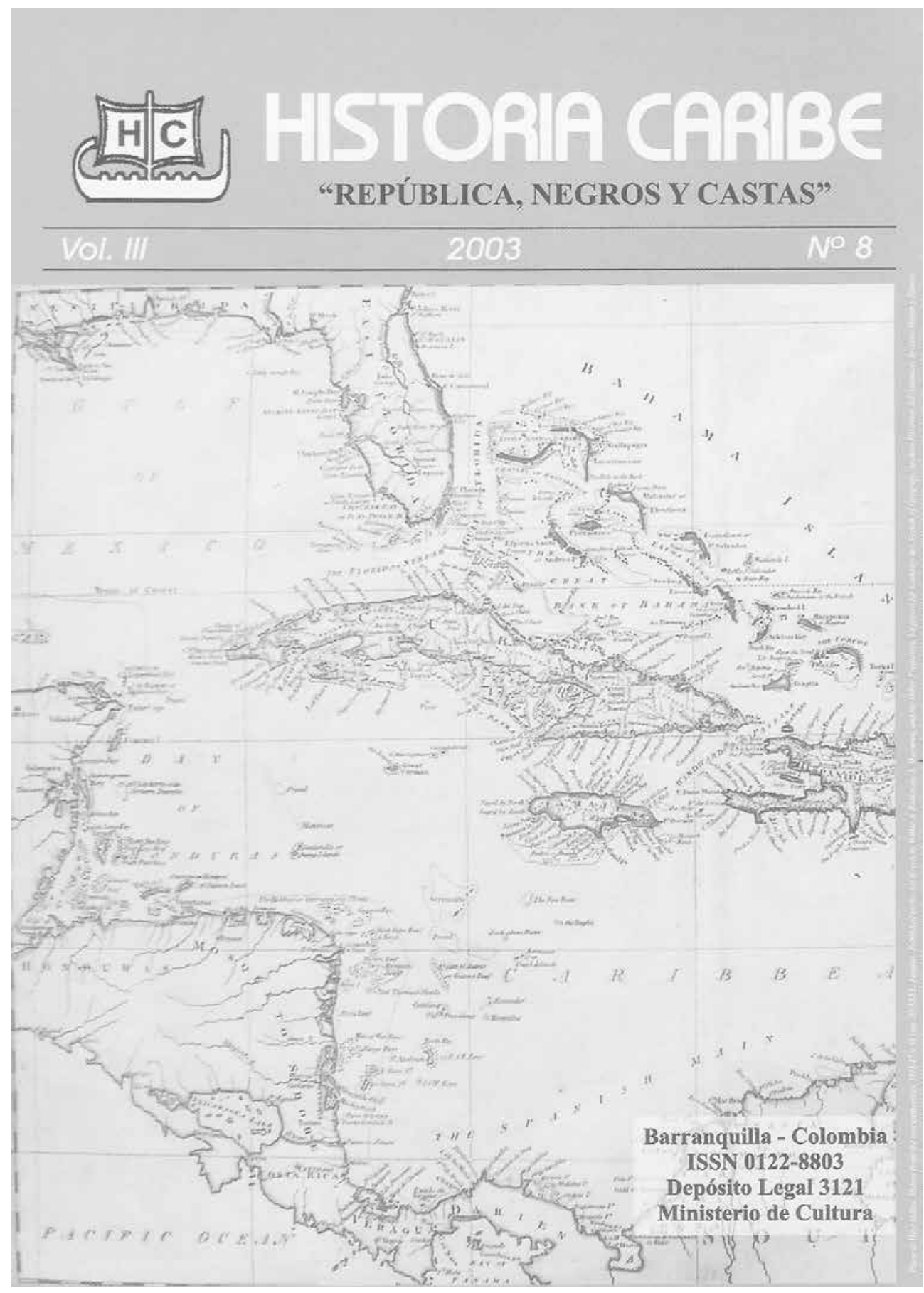




\section{Entre la inconstancia y la incuria: La experiencia fallida de los pueblos de misión chimilas a finales del siglo XVIII, en las llanuras del Caribe*}

\section{Marcela Quiroga Zuluaga}

Profesora de la maestría en Estudios Sociales de la Universidad Pedagógica Nacional (Colombia). Correo electrónico: marcelaquirogafr@yahoo.fr. Doctora en Historia y Civilizaciones del Ecole des Hautes Etudes en Sciences Sociales (Francia) y Antropóloga de la Universidad Nacional de Colombia (Colombia). Entre sus publicaciones recientes se encuentran: "El proceso de reducciones entre los pueblos muiscas de Santafé durante los siglos XVI y XVII", en Historia Crítica, No. 52 (2014) y “La encomienda entre los pueblos de la provincia Paez en el siglo XVII”, en Fronteras de la Historia, Vol. 15, No. 1 (2010). Entre sus líneas de investigación tenemos los temas de antropología histórica e historia colonial.

Recibido: 31 de marzo de 2014

Aprobado: 16 de junio de 2014

Modificado: 25 de agosto de 2014

Artículo de reflexión

DOI: http://dx.doi.org/10.15648/hc.26.2015.9

Este artículo forma parte del proyecto "La domination coloniale au pluriel: Le pouvoir colonial et la conquête des peuples Muiscas, paeces et chimilas dans la Nouvelle Grenade", realizado para obterner el título de doctorado en Historia y Civilización del Ecole des Hautes Etudes en Sciences Sociales (Francia).

Esta publicación está bajo una licencia Creative Commons Reconocimiento-Compartir Igual 3.0

\section{(cc) BY-SA}


Entre la inconstancia y la incuria: La experiencia fallida de los pueblos de misión chimilas a finales del siglo XVIII, en la llanuras del Caribe

\begin{abstract}
Resumen
A partir de la documentación hallada en distintos archivos, este artículo observa las vicisitudes del proceso de constitución de los pueblos de misión chimilas, luego de su derrota bélica a finales del siglo XVIII. A pesar de su fracaso, en el contexto colonial este proceso puede ser considerado el inicio del fin de una larga historia de confrontación entre indígenas y españoles.
\end{abstract}

Palabras clave: Chimilas, pueblos de misión, Gobernación de Santa Marta.

Between fickleness and carelessness: The failed chimila missions at the end of the 18th-Century in the Caribbean

\begin{abstract}
Based on archival documents, this article explores the difficulties surrounding the formation of Chimila Missions after the Chimila Indians' military defeat at the end of the eighteen-century. Despite their collapse, the eighteen-century Chimila missions marked the end of a long history of armed struggles between Spaniards and Indians.
\end{abstract}

Key words: Chimilas, mission towns, Governor of Santa Marta.

Entre a inconstancia e a incuria: a experiência falhida dos povos de missão Chimilas no final do século XVIII, na planícies do Caribe

\title{
Resumo
}

A partir da documentação encontrada em diferentes arquivos, este artigo analisa as vicissitudes do processo de constituição dos povos da missão Chimilas, depois de sua derrota militar no final do século XVIII. Apesar de seu fracasso, no contexto colonial, este processo pode ser considerado o começo do fim de uma longa história de confronto entre índios e espanhóis.

Palavras-chave: Chimilas, povos de missão, Governação de Santa Marta. 


\section{Entre l'inconstance et l'incurie: L'expérience manquée des peuples de mission Chimilas à la fin du XVIIIe siècle dans la plaine des Caraïbes}

\section{Résumé}

En partant de la documentation de différentes archives, cet article présente la complexité du processus d'agencement des pueblos de missions parmi les peuples Chimilas de la Gobernación de Santa Marta au sein de la Nouvelle Grenade. En effet, après que ce peuple soit vaincu par les expéditions armées à la fin du XVIII siècle, ce processus peut être considéré comme le début de la fin d'une longue confrontation entre ces indiens et les espagnols.

Mots-clés: Chimilas, pueblos de mission, Gobernación de Santa Marta.

\section{INTRODUCCIÓN}

Durante todo el periodo colonial, la "nación chimila" localizada en el centro de la gobernación de Santa Marta fue uno de los íconos más importantes de la resistencia indígena contra la dominación española en la Nueva Granada ${ }^{1}$. En efecto, como es conocido, por más de dos siglos estos pueblos con sus acciones bélicas contuvieron la ocupación española en la región, lo cual contribuyó a la construcción de una representación,

1 Existen numerosos trabajos que tratan de los chimilas, sus estrategias de resistencia y los distintos mecanismos desplegados por el poder español para su pacificación durante la Colonia; entre estos se pueden mencionar: Orlando Fals Borda, Historia doble de la Costa 1. Mompox y la Loba (Bogotá: Universidad Nacional de Colombia - Banco de la República - Áncora Editores, 2002), 103a/103b115a/114b; Carlos Alberto Uribe, "La rebelión chimila en la provincia de Santa Marta, Nuevo Reino de Granada en el siglo XVIII", Estudios Andinos No. 13 (1977): 163-165; Lola Luna, "La Nación Chimila: Un caso de resistencia indígena en la nación de Santa Marta", En Conquista y resistencia en la historia de América, eds. Pilar García Jordán, (Barcelona: Universitat de Barcelona, 1991), 123-137; Lola G: Luna, Resguardos coloniales de Santa Marta y Cartagena, y resistencia indígena (Bogotá: Fondo de Promoción de la Cultura, 1993), Martha Herrera Ángel, Ordenar para controlar, ordenamiento espacial y control político en las llanuras del Caribe y en los Andes centrales Neogranadinos, siglo XVIII (Bogotá: Instituto Colombiano de Antropología, 2002); César Augusto Mendoza Ramos, "La provincia de Santa Marta: Espacio y poblamiento 1780-1810, Amauta No. 14 (2009): 29-54; Édgar Rey Sinning, Poblamiento y resistencia: los chimila frente al proceso de ocupación de su territorio (Santa Marta: Gobernación del Magdalena- Edición al cuidado de Conexión Cultural Editores, 2012), David J. Luquetta Cediel y Antonio Vidal Ortega, "La vida material del otro lado de la frontera colonial: los pueblos chimilas en la segunda mitad del siglo XVIII", Diálogos, Revista electrónica de historia, Vol. 15, No. 1 (2014): 211-233. 
desde el punto de vista español, del indígena basada en su "salvajismo" y "barbarie". Representación, igualmente, sustentada en la lectura española de una realidad indígena caracterizada por la fragmentación socio-política y territorial. Pues los chimilas, como otros grupos categorizados por los españoles como "sin Dios, sin rey y sin ley" configuraron, en realidad, una serie de archipiélagos independientes, cuyas formas de relación política y de construcción social, en parte estuvieron orientadas por una guerra de tipo convencional ${ }^{3}$. De esta manera, los españoles no confrontaron un grupo socio-político homogéneo y unificado, sino múltiples fracciones móviles y dispersas, cuyas estrategias tradicionales de guerra fueron reorientadas para combatir la ocupación española.

A pesar de que los grupos chimilas mantuvieron una posición ofensiva frente a la dominación colonial durante los siglos XVII y XVIII, conocida como la "rebelión chimila", solo hasta la segunda mitad del siglo XVIII

2 Julián Antonio, La perla de América, Provincia de Santa Marta, reconocida y observada y expuesta en discursos históricos (Madrid: Editor Don Antonio de Sacha, 1787), 158.

3 Desde un punto de vista antropológico, es muy difícil determinar a través de las fuentes documentales si los chimilas configuraron un solo grupo étnico o varios, pues las informaciones de los españoles al respecto, son poco claras y parecen confundir distintos niveles de integración socio-política entre estos grupos, caracterizados por su atomización y relaciones flexibles. Así podemos preguntarnos, si por ejemplo, los distintos grupos mencionados a lo largo del siglo XVIII por el cronista Nicolás de la Rosa, como 'alcoholados', los tomocos y los orejones relacionados por este autor con los chimilas, formaron diferentes tribus o si bien estos configuraron segmentos tribales, en los términos expuestos por el antropólogo Evans-Prichard. Es decir, si los distintos pueblos y parcialidades chimilas mencionadas en las fuentes documentales no fueron subdivisiones políticas y territoriales e independientes al interior de un conjunto socio-cultural mayor del tipo de una tribu, como ha sido expresado por el antropólogo Carlos Alberto Uribe. En el siglo XVIII, los españoles denominaron bajo este apelativo una serie de grupos mal conocidos por ellos y aún hoy en día, localizados en la provincia "chimila" que opusieron una fuerte resistencia a la expansión colonial. En este sentido, autores como Martha Herrera, al igual que Reichel-Dolmatoff sugieren que el término chimila constituyó una categoría para caracterizar una serie de grupos étnicos que fueron caracterizados indistintamente como "chimila" o "caribes" para facilitar su identificación y estigmatización. Sin embargo, como se ha mencionado, si toma en cuenta las características de la sociedad chimila en la cual las principales formaciones socio-políticas y territoriales no superaron el grupo local es posible que los chimilas hayan constituido una tribu configurada por varios segmentos cuyas relaciones fueron cambiando y afirmándose contra la ocupación española. José Nicolás de la Rosa, Floresta de la Santa Iglesia Catedral de la Ciudad y Provincia de Santa Marta (Bogotá, Banco de la República, 1975), 221, 279 y 291; Edwards Evans-Pritchard, Les Nuer (Paris: Gallimard, 1975); Carlos Alberto Uribe, "Un antropólogo sueco en Colombia, Gustaf Bolinder", Revista del Banco de la República, No. 18 (1987) 6; Gerardo Reichel-Dolmatoff, Datos histórico-culturales sobre las tribus de la antigua Gobernación de Santa Marta (Bogotá: Banco de la República, 1951), 43; Martha Herrera, Ordenar para controlar..., 260. 
la administración española construye un proyecto claro de sometimiento, distinto a las expediciones puntuales y punitivas que habían caracterizado el siglo anterior ${ }^{4}$. Este nuevo interés por "pacificar" la población indígena se inscribió en un contexto global más amplio orientado por las disposiciones y medidas tomadas por la Corona española a mediados del siglo XVIII, conocidas como las reformas borbónicas. Bajo este impulso reformista, que tuvo entre sus principales objetivos la explotación eficaz de los recursos de las colonias, la "pacificación" de los pueblos indígenas no sometidos y la ocupación de sus territorios constituyó uno de los principales objetivos de la administración colonial ${ }^{5}$. En el caso de la gobernación de Santa Marta, por ejemplo, los chimilas localizados en el centro de su territorio había impedido su desarrollo económico y optimizar sus riquezas, configuradas principalmente por la tierra que ocupaban, la explotación ganadera y otros recursos naturales existentes en su territorio ${ }^{6}$.

Pero además de la optimización económica de los recursos, a partir de estas políticas fueron impulsadas otras disposiciones que tuvieron repercusiones sociales, como por ejemplo, la configuración de nuevas directrices poblacionales y de control social, que buscaban ordenar una realidad social diversa y mestiza que había emergido a lo largo de la dominación colonial. Es precisamente en este contexto que se inicia el proyecto de sometimiento de la población chimila, entre los años de 1745 y 1765, el cual, siguiendo la orientación de las políticas borbónicas estuvo determinado por el desarrollo de estrategias de contención de la población indígena rebelde, fundadas en el control y ordenamiento territorial. La construcción de caminos, y el célebre proceso fundacional y de reorganización socio-territorial de la población libre y mestiza impulsado por el Virrey Eslava, y llevado a cabo, en la gobernación de Santa Marta, por el maestre de campo José Mier y Guerra forman parte de este proceso $^{7}$. Sin embar-

4 Carlos Alberto Uribe, "La rebelión chimila en la provincia de Santa Marta Nuevo Reino de Granada en el siglo XVIII”, Estudios Andinos No. 13 (1977): 163-165.

5 César Augusto Mendoza Ramos, "La provincia de Santa Marta...”, 49.

6 Germán Colmenares, Relaciones e informes de los gobernantes de la Nueva Granada (Bogotá: Biblioteca de Banco Popular, 1989), 186-187.

7 Numeroso trabajos dan cuenta de este proceso entre estos se pueden mencionar: Orlando Fals Borda, Historia doble de la Costa 1.., 103a/103b-115a/114b; Lola Luna, "La Nación Chimila...", 123-137; Resguardos coloniales ...,74-77; Martha Herrera Ángel, Ordenar para controlar..., 270279, César Augusto Mendoza Ramos, "La provincia de Santa Marta..." 29-54; Édgar Rey Sinning. Poblamiento y resistencia...,136-164. 
go, su objetivo principal, más allá de lograr la sumisión indígena, fue el control del territorio chimila a través de villas de contención, permitiendo una expansión colonial que hasta el momento había sido impedida por la continua resistencia indígena ${ }^{8}$.

Un segundo momento, muy distinto al anterior, puede ser observado entre las décadas de los 60 y los 70, con la configuración de un proyecto de "pacificación" indígena cimentado en las armas, bajo la forma de entradas generales cuyas acciones lindaron con métodos de exterminio de la población indígena ${ }^{9}$. A finales del siglo XVIII, estas nuevas acciones arrojaron como resultado la salida voluntaria de las fracciones chimilas; es en este momento que la administración española puso en obra otro tipo de mecanismos de control de la población indígena, relacionados con aquellos objetivos ideales sobre los cuales se había legitimado, durante siglos, la dominación española entre las poblaciones americanas, a saber, su "civilización” y "transformación”. En este caso, como el de muchos de los pueblos americanos que opusieron una fuerte resistencia al poder español, dicho proceso será proyectado a través de los procesos de congregación de la población indígena en pueblos de misión.

Las características de este proceso que puede ser concebido, como otro momento en el ciclo de la "pacificación" chimila será el objetivo central de este artículo. A partir de la observación de distintas fuentes documentales de finales del siglo XVIII producidas por los administradores coloniales y misioneros, se observará un momento menos conocido de la historia del sometimiento chimila, el cual a pesar de su fracaso permitió redefinir la larga historia de confrontación entre los indígenas y los españoles.

\section{El preÁmbulo a los pUeblos de misión: las eNTRAdAS MiXTAS}

Si bien las expediciones guerreras como dispositivo de reducción ya ha-

8 En la región gran parte de la expansión de esta frontera estuvo ligada al fortalecimiento de la explotación ganadera y a la demanda de la población mestiza por tierras para ejercer esta actividad. Al respecto ver: Hugues Rafael Sánchez Mejía, "Composición, mercedes de tierras realengas y expansión ganadera en una zona de frontera de la gobernación de Santa Marta: Valledupar (1700-1810)". ACHSC Vol. 39 No. 1 (2012): 81-117.

9 Sobre los distintos mecanismos de sometimiento español chimila ligados a la guerra. Ver: Martha Herrera Ángel, Ordenar para controlar... 270, 280. 
bían sido preconizadas por la administración colonial entre los chimilas, a partir de 1763 podemos constatar un viraje en este esquema de pacificación. No solo porque las entradas contra este pueblo fueron intensificadas sino también porque su puesta en obra se desprendió del desarrollo de un proyecto de pacificación concreto destinado a su reducción y control. Ya no se trataba de incursiones esporádicas para castigar los ataques de los indios sino de una guerra ofensiva contra los indios, "enemigos internos" de la Corona ${ }^{10}$. Para adelantar esta nueva etapa de la guerra contra los chimilas fue, entonces, necesario fortalecer el desarrollo de un orden militar particular en la región. Podemos constatar, así, la conformación de cuerpos militares como las milicias bajo el mando de capitanes a guerra ${ }^{11}$. En realidad, este tipo de mecanismo de pacificación de la población indígena no era inédito, y había sido empleado en el contexto de la guerra contra los ingleses. Se trataba de corporaciones de defensa y de disuasión sostenidas tanto económica como físicamente por los habitantes de los distintos pueblos y ciudades. En el contexto de la pacificación chimila, esta forma de organización militar que tenía a priori un fin defensivo y puntual tuvo durante la segunda mitad del siglo XVIII un carácter permanente.

La consolidación del proyecto de pacificación chimila, propuso igualmente, la integración de nuevos agentes: los misioneros de la orden Capuchina de Valencia, quienes habían llegado a la provincia de Santa Marta "para extensión del domino del Rey y de la luz del evangelio" en el año de 1746, y además habían logrado (entre 1750 y 1762) la pacificación de los tocaimos y de otros pueblos rebeldes del sur-oriente de la gobernación ${ }^{12}$. Un logro poco despreciable, pues los frutos de la pacificación chimila serán en

10 Martha Herrera., Ordenar para controlar..., 280.

11 Se trataba de autoridades civiles, corregidores o alcaldes, que podían ocuparse de los asuntos de la guerra,

12 [1765] Archivo General de la Nación (AGNC), Conventos t. 15, f. 536v. Desde finales del siglo XVII, los misioneros capuchinos de Valencia habían llegado a La Guajira provenientes de Maracaibo, a lo largo de la primera mitad del siglo XVIII, su territorio de acción se extendió a la gobernación de Santa Marta. Este territorio comprendió de oriente a occidente, desde las costas orientales del Golfo de Maracaibo hasta el río Magdalena; y de norte a sur, desde las costas del mar Caribe hasta la ciudad de Ocaña. José Polo Acuña, "Contrabando y pacificación en la frontera colombo-venezolana”, América Latina en la Historia Económica No. 24 (2005): 101. 
gran parte obtenidos, gracias a su participación en las diversas incursiones bélicas realizadas en su territorio ${ }^{13}$.

La guerra contra los chimilas fue así regida por la acción conjunta de los misioneros y sus escuadras de indios flecheros y rastreros, así como de las milicias de ciudades como Santa Marta, Valencia de Jesús, y aquellas que habían sido fundadas por Mier y Guerra a lo largo del río Magdalena a finales de la primera mitad del siglo XVIII. Bajo la forma de entradas generales estos cuerpos militares se internaban en el territorio indígena siguiendo sus huellas y alcanzando sus sitios de habitación para su destrucción. Se trataba de una caza al "indio", cuyo objetivo, además de capturarlo fue el reconocimiento y la inspección de un territorio hasta el momento totalmente desconocido para los españoles. Aunque estas entradas no posibilitaron un control territorial continuo y estable, en razón de su intensidad y frecuencia, no podemos negar los efectos producidos por esta etapa del proceso de pacificación indígena, pues dichas incursiones generaron un conocimiento geográfico y poblacional que permitió definirlos mejor como objetivo militar ${ }^{14}$.

De toda evidencia, durante este periodo tanto para la administración colonial como para los misioneros, por encima del enunciado de la conversión y de la evangelización primaba la idea de despejar el territorio indio en beneficio de los españoles, como claramente lo expresaba el prefecto Capuchino encargado de su reducción: "que por todo lo que respecta a los chimilas gentiles los indios de mis misiones se obligan con todo esmero a sacar los que pudieren y dejar la tierra limpia libre de tales insultos"15. Podemos, aún, preguntarnos si estas expediciones guerreras no se proponían liquidarlos, como lo muestra la opinión del mismo prefecto, quien corroboraba: “'Que] jamás podrá verificarse la total pacificación [de los chimilas] sin la observancia de lo mandado por vuestra excelencia en extinguir los indios grandes y sacar solo indios chinas y chinos para su conversión"16.

13 Édgar R. Sinning, Poblamiento y resistencia...169-200.

14 Una presentación de las distintas entradas y de las acciones de destrucción de los sitios indígenas entre 1763 y 1767 puede ser observada en: José de Mier y Guerra, Poblamientos en la Provincia de Santa Marta, siglo XVIII, t. 2 (Bogotá: Libreros Colombianos, 1987). Ver igualmente, Martha Herrera, Ordenar para controlar..., 284-285.

15 [1765] AGNC, Conventos, t. 5, f. 495r.

16 [1774] AGNC, Conventos, t. 5, fol. 533v. 
Si parece imposible percibir la reacción de los pueblos chimilas frente a la ofensiva española, la documentación muestra que las consecuencias de la guerra adelantada contra ellos fueron significativas. De acuerdo, con las informaciones de los indios capturados en la expediciones, los chimilas "se hallan atemorizados con las correrías que están viendo, y lo acosados que los tienen los indios de las misiones Puentes y Tocaimo"17. De hecho, estas incursiones bélicas promovieron su dispersión y migración, así por ejemplo, las parcialidades chimilas que habitaban el centro de la provincia -en las llanuras de San Ángel y aquellos de los ríos circunvecinos de la ciudad de Valencia de Jesús- se habrían desplazado en cercanías de la ciudad de Tenerife ${ }^{18}$. De la misma manera, para 1771, de acuerdo con los informes de los Capuchinos y del cabildo de la ciudad de Valencia de Jesús, gracias a estas múltiples expediciones, se habían logrado reducir más de 200 almas en los pueblos de misión tocaimos. En gran parte el éxito de estas incursiones, estaba dado por la intervención de estos indígenas, quienes no solo conocían el territorio chimila, sino además compartían los códigos de una guerra de cercanía, fundada en estrategias como la razia $y$ la vendetta ${ }^{19}$. Desde cierto punto de vista, las guerras de la pacificación chimila delimitaron un espacio en el cual los pueblos tocaimos reducidos pudieron prolongar sus antiguas prácticas belicosas, recibiendo, a la vez, una gratificación económica ${ }^{20}$.

En 1774, estimulado por los logros que comenzaban arrojar las expediciones contra los chimilas, y por solicitud del padre prefecto de las misiones capuchinas, el Virrey Manuel Guirior establece un nuevo cargo militar destinado a conducir de manera permanente el proceso de pacificación. Esta tarea fue encargada al vecino de la ciudad de Valencia de Jesús, Agustín de la Sierra, quien fue nombrado oficialmente "Capitán Comandante de la pacificación de los indios chimilas" 21 .

17 [1767] AGNC, Milicias Marina, t. 124, f. 334r.

18 AGNC, Milicias Marina, t. 124, f. 332v; Empleados Públicos, t. 31, f. 332r.

19 [1766] AGNC, Milicias Marinas t. 146, f. 160r.

20 [1774] AGNC, Conventos t. 15, f. 533r.

21 En el ambiente de la guerra promovido por los participantes locales del proceso de pacificación chimila, Agustín de la Sierra será reconocido como el Capitán de Conquistas de los Chimilas. AGN, Conventos t. 15, f. 534r.; sobre de La Sierra ver igualmente: María Dolores Luna, "La Nación Chimila...",135; Edgar R. Sinning, Poblamiento y resistencia...169-200. 
La Sierra pondrá en obra otras estrategias de sometimiento y buscará establecer un tipo de relación fundada, esta vez, en la persuasión y la disuasión indígena. Él se servirá de los indios chimilas sometidos bajo la tutela de las misiones capuchinas que ya habían aprendido el español, como lenguaraces e intermediarios a fin de extraer voluntariamente los indígenas de las montañas ${ }^{22}$. En esta misma perspectiva, inició la fundación de pueblos y realización de labranzas destinados a acogerlos, e igualmente, dio lugar a un intercambio de utensilios de origen hispánico que, parece, no fue del todo indiferente a los chimilas. Se trataba, principalmente, de herramientas y objetos decorativos de origen español, como machetes, hachas, palas, cuchillos, navajas, las piezas de lienzo, anillos, chaquiras, etc. A través de estos dones no se trataba tan solo de deslumbrar a los indígenas con regalos novedosos sino de atraerlos procurándoles objetos que ya habían sido apropiados por ellos, a través de sus distintos ataques a los asentamientos españoles.

En la práctica, estas estrategias adelantadas por La Sierra se corroboraron exitosas, después de más de un siglo de guerra entre 1775 y 1777 los chimilas iniciarán numerosas salidas masivas y voluntarias ${ }^{23}$. Desde un punto de vista histórico sus maniobras señalan un nuevo momento en el proceso de la pacificación indígena, pues forjaron un espacio inédito de "paz" distante de las acciones de "sangre y fuego" empleadas durante décadas por la administración colonial.

La documentación concerniente a este periodo tendería a mostrar que los chimilas depusieron las armas en parte, no solo por las pérdidas conducidas por la presión militar de las acciones conjuntas de los tocaimos y españoles, y los dones españoles sino también por las epidemias que los azotaban, como lo testimonia La Sierra: "aunque comprendo según noticias de los que han salido ser fácil la entrega de todos y más en la actualidad [porque] padecen enfermedades de que aseguran morir muchos"24. De

22 Estos indígenas fueron gratificados con un salario mensual de 4 pesos. [1775] AGN, Empleados Públicos, t. 13, f. $724 \mathrm{r}$.

23 [1775] AGNC, Empleados Públicos, t. 13, f. 648r à 668r; 703r, 745r; [1776] Empleados Públicos t. 10, f. 993 r a $997 v$; [1777] Caciques e Indios, t. 46, f. 22r.

24 [1775] AGNC, Empleados Públicos, t. 13, f. 748r. 
acuerdo con los testimonios documentales los indígenas se encontraban fragilizados tanto por una guerra que se había intensificado y volcado contra ellos, como por las enfermedades. Pero, a pesar de la derrota y fatiga de las parcialidades chimilas que describen las fuentes, la entrega indígena fue condicionada y negociada, pues solo será obtenida por la dinámica del intercambio establecido por La Sierra, cuya base fue la constitución de pueblos y la oferta de herramientas. Así, las distintas parcialidades se entregaron, pero solo una vez que los pueblos fueran formados por los españoles.

\section{LOS PUEBLOS DE MISIÓN CHIMILAS}

El proceso de congregación de los chimilas siguió los contornos de una realidad indígena fragmentada socio-políticamente, en gran parte, porque dicho proceso fue el resultado de la negociación entre los españoles y una serie de fracciones socio-políticas que no guardaban ningún vínculo de unión entre sí, más allá de las confederaciones contextuales tejidas en el marco de la resistencia bélica contra los españoles. En consecuencia a lo largo de la dinámica de constitución de los pueblos, los chimilas a lo largo del proceso de negociación para su reducción tratarán de conservar la autonomía territorial y socio-política descrita siglos antes para los grupos locales de las tribus de la región ${ }^{25}$. En este sentido, las poblaciones chimilas siguieron las líneas de demarcación de los archipiélagos sociopolíticos que formaban sus "parcialidades", como lo testimonia de La Sierra en 1776:

“aunque por su natural inconstancia deberá estar V(uestra) S(eñoria) en la inteligencia que no pararán, pues siendo tan andariegos y propensos de vaguear, se presentan en todas partes y más donde los regalan y dicen que allí quieren pueblo y les dura el pensamiento muy poco, a que se agrega que son de una naturaleza total// enemiga unos de otros, queriendo cada familia por sí un pueblo"26.

25 Algunas de las características socio-políticas de los chimilas son descritas en las primeras relaciones del siglo XVI, al respecto ver: "Descripción de la ciudad de Tamalameque en la Gobernación de Santa Marta" y "Descripción de la villa de Tenerife de las cosas de la tierra que mando azer el muy Ilustre señor don Lope de Orozco, G(obernad)or perpetuo y capitán general de la Ciudad de Santa y sus provincias por su Majestad”, en Relaciones y Visitas a los Andes, siglo XVI. T. II, Región Caribe, Hermes Tovar (Bogotá: Colcultura-Instituto Colombiano de Cultura Hispánica, 1993).

26 AGNC, Caciques e Indios t. 46, f. 224r. 
A pesar de las dificultades que propusieron las prácticas indígenas como el nomadismo y la fragmentación socio-política, el proceso poblacional entre los chimilas fue iniciado en 1775 con la congregación de dos fracciones indígenas localizadas en los sitios de Pajaral y el río Ariguaní, en los flancos occidentales de la Sierra Nevada. Guardando su autonomía y diferenciación socio-política estas parcialidades dieron origen a los pueblos de San Antonio del Rosario y Guarupal de Jesús ${ }^{27}$. Posteriormente, bajo la misma dinámica impuesta por los indígenas, en 1777 fueron fundados el pueblo de San Joseph de las Pavas, Punta Gorda, en las márgenes del río Magdalena y Catarina (Divina Pastora) en el centro de la provincia ${ }^{28}$. Para 1777 estos cinco pueblos congregaban todas las fracciones chimilas bajo la tutela de los misioneros capuchinos, encargados de entablar su proceso de reducción y de evangelización ${ }^{29}$.

En términos generales los pueblos de misión tenían la misma función de los pueblos de indios coloniales, es decir, reducir la población indígena a la "vida en policía" y su evangelización. Sin embargo, estos se diferenciarán netamente de los últimos, en cuanto estos configuraron una empresa de civilización a tiempo completo. Los pueblos de misión albergaban "misiones vivas", constituyendo un espacio en el cual la práctica de los misioneros era permanente, y cuyo objetivo era inculcar los preceptos básicos de la vida en sociedad que escapaban a estas sociedades "sin Dios, ley, ni rey", y que a ojos de los españoles eran una condición preliminar a la aceptación del evangelio. Las misiones delineaban, así, un mecanismo de dominación colonial fundado en la representación española de la "barbarie y salvajismo" de aquellas sociedades americanas cuyas formas de organización territorial y socio-política se oponían desde todo punto de vista a la sociedad española. El testimonio del obispo del Nuevo Reino de Granada a finales

27 De acuerdo con los censos realizados en 1776 en el pueblo de Garupal fueron congregados 178 indígenas y en el de San Antonio 232. [1776] AGN, Empleados Públicos, t. 10, f. 989r a 990r.

28 [1777] AGNC, Caciques e Indios, t. 46 f. 223r Así lo testimonia una relación de las fundaciones hecha por Agustín de la Sierra: “(...) Al mismo efecto pidieron pueblo otros varios indios y se les dio en el paraje que se nombra Punta Gorda orillas del río Magdalena (...) Con igual miras pidieron pueblo los indios de Potrero Grande, parcialidad de la misma nación que se les dio en un paraje llamado Catarina (...)" [1779] Archivo Provincial de los Capuchinos de Valencia (APCV) 07132, f. 2r. [1777] APCV, 007132/2. 
del siglo XVIII sobre la manera en que debían actuar las misiones de este territorio, y entre ellas las chimilas, ilustra bien esta percepción:

"Aprovéchense los preciosos momentos en que los indios obligados de la necesidad o movidos de la natural inclinación del hombre a vivir en sociedad, van a buscar a los misioneros, atemperándose en principios a las escasas luces de su obscura racionalidad. Hágase conocer las ventajas y comodidades de la vida civil y política, aprendan nuestras lenguas y nuestras costumbres, dejen de ser brutos, empiecen a ser hombre y enséñeseles después a ser cristianos. Dios libre a un obispo de la Iglesia Católica de sentar proposición alguna que pueda retardar la propagación del Evangelio, pero el interés mismo de la religión pide no se arrojen margaritas a los puercos, y cuando aquellas almas brutas no se hallan en estado de conocer las verdades sublimes del cristianismo, en necesario disipar antes las tinieblas en que están sumergidos, por medio de ideas y conocimientos análogos a su actual situación, y conducirlas como por grados a la luz del Evangelio" 30 .

Las misiones entre los pueblos "bárbaros y salvajes" actuaban no solo como un mecanismo para erradicar las "malas costumbres" de los indios vía la evangelización, sino también como un dispositivo para involucrarlos en la creación de un nuevo mundo social que imponían las condiciones de la dominación española. Se trataba de un mundo social forjado de toda pieza sobre una reforma de la realidad indígena. A través, tanto de la imprenta de nuevas estructuras cognitivas como de la conformación de nuevas relaciones sociales, normativas, económicas y socio-políticas, de las cuales los pueblos de misión eran el escenario. Así, las misiones constituían un tipo de saber-poder cuyo objetivo era transformar la realidad indígena desde su interior, interiorizando al mismo tiempo esta transformación ${ }^{31}$. En este sentido, la acción misionera y sus pueblos sobrepasaban el objetivo de la

30 [1789] Relación del estado del Nuevo Reino de Granada que hace el obispo de Córdoba a su sucesor, el excelentísimo señor Fray don Francisco Gil y Lemos, en Órdenes Religiosas de España y la Colonización de América, Otto Mass (Barcelona: Fidel Giro Impresor, 1918).

31 Sobre las misiones como dispositivo del poder español, ver: Guillaume Boccara, Guerre et ethnogenèses mapuche dans le Chile Colonial (París: L’Harmattan, 1998), 251. 
congregación espacial de los indios y de la evangelización, principales evidencias de la "vida en policía".

Entre los chimilas la inscripción de los indios en esta nueva realidad fue sustentada no solo en la necesidad de fijarlos territorialmente, sino también en la transformación de las formas de subsistencia. Es en esta dinámica que debemos contextualizar los regalos de herramientas otorgados a los indios a la hora de su reducción, y las áreas de cultivos realizadas para recibir los chimilas que salían de las montañas, como lo testimoniaba en 1788 Antonio Narváez de la Torre, Teniente de Cartagena:

"Los pueblos barbaros y salvajes que viven solo de la caza, como estos indios llegan a un cantón o terreno se arranchan allí, persiguen y matan animales que hay para su sustento y los demás se ahuyentan, faltándoles poco a poco la caza y por consistente su subsistencia levantan el Real y van a buscarlo a otro paraje (...) por esto se les han trabajado rozas y sementeras que se les han entregado para su sustento, se les ha procurado dedicar suavemente a trabajar en ellas dándoles herramientas, se les han suministrado, vestuarios se les han establecido al mismo tiempo que ellos algunos españoles a cuyo ejemplo se apliquen al trabajo y sean tomado otros arbitrios" 32 .

El cambio de apariencia y de las formas de subsistencia que alentaban estos dones constituían los primeros pasos de la transformación de la realidad chimila. Pero a estos elementos se adicionaban otros, como los cambios de los ritmos de trabajo, de las pautas residenciales que se proponían los pueblos centralizados, y a nivel político, la redefinición de relaciones inéditas de autoridad como las que forjaba el cargo del capitán indio ${ }^{33}$. Por su perennidad y por su sentido esta nueva institución rompía toda la dinámica de atomización política indígena, figura de una nueva autoridad, simbólicamente diferenciada por el bastón de mando que le era otorgado al momento de su elección así como por su vestido; esta nueva forma de gobierno trazaba las líneas del nuevo campo socio-político unificado y

33 [1775] AGNC, Empleados Públicos, t. 13, f. 703r; [1776] Caciques e Indios, t. 46, f. 220r, 517r. 
jerarquizado que los españoles pretendían definir a través del pueblo colonial ${ }^{34}$.

Desde el punto de vista territorial, político y normativo los pueblos de misión chimila configuraban una experiencia totalmente novedosa para estos indígenas caracterizados por la atomización socio-política y territorial, y, en cierta medida, los españoles eran conscientes de esto. Es por esta razón que para la afirmación de este espacio, crisol, en el cual debía generarse la transformación de los chimilas, bajo el mando de los misioneros, la administración colonial puso en marcha otros mecanismos y agentes originales. Se trata de la integración a los pueblos de familias no indígenas para la "custodia" de la población indígena reducida ${ }^{35}$.

El pueblo de misión se proyectaba así como un espacio de interiorización de la norma conducido tanto por las instrucciones de los misioneros como por la convivencia y socialización de los indígenas con españoles y "libres de todos los colores”. Si tomamos en cuenta las políticas segregacionistas promulgadas por la Corona esta disposición que favorecía la mezcla de indígenas y gentes de otras castas no deja ser sorprendente. Pero, debemos señalar que en ciertos contextos locales del virreinato, desde la segunda mitad del siglo XVIII, las políticas segregacionistas fueron aventajadas por políticas de poblamiento y de expansión colonial ${ }^{36}$. En este contexto, a pesar de su ambigüedad jurídica, los pueblos mixtos de chimilas y españoles beneficiaban tanto los intereses coloniales fundados en el desarrollo económico y territorial de la región, como el ideal de civilización indígena. Así, por ejemplo el padre Antonio de Muro, visitador de las misiones chimilas declaraba en 1781:

"Las ventajas que pueden seguirse del fomento de esta misión, además de la salvación de tantas almas son el tener transitable el camino desde la ciudad del Valle de Upar y Valencia de Jesús a

34 Este proceso de redefinición política puede ser observado igualmente en otros espacios misionales como entre los pueblos guaraníes, Guillermo Wilde, Religión y poder entre las misiones de guaraníes (Buenos Aires: Editorial Sb. 2009).

35 [1775] AGNC, Empleados Públicos, t. 13, f. 723r.

36 Magnus Mörner, "Las comunidades de indígenas y la legislación segregacionista en el Nuevo Reino de Granada", Anuario de Historia Social y de la Cultura, Vol. 1 (1963): 63. 
Cartagena, por el tránsito de ganados y el comercio libre, como así mismo el camino que se ha abierto desde estas dos ciudades a Mompox (...). Y lo que importa más, queda ya sin riesgo todo el río Magdalena desde su desembocadura en el mar hasta el Banco. De suerte que lo que hace seis años no se podía transitar sino con mucha gente y peligro por temor de los indios esparcidos por todo este terreno, hoy por la misericordia de Dios se han reducido y pacificado en sólo cinco pueblo donde residen (...). Además tenemos tres cortes o astilleros de madera preciosa que sacándose al río Magdalena por el río Cesar (...) se transporta con facilidad a Cartagena (...)"37.

En esta imagen victoriosa de los españoles, no se ha de ver un éxito total para el campo español. Pues, las informaciones de los capuchinos que siguieron a este primer periodo fundacional nos permiten observar que tanto el proceso de congregación como el de reducción se comprobarán mucho más complejos y penosos. En consecuencia, gran parte de los objetivos que se proponían los pueblos de misión o las misiones serán alcanzados escasamente $y$, vistos de manera global, podemos decir que fueron todo un fracaso. En efecto, para que un dispositivo tal como las misiones pudieran alcanzar sus objetivos de transformación de la realidad indígena era necesario, antes que todo, consolidar el proceso de congregaciones, "fijando" de forma permanente los indígenas en los pueblos de reducción, lo que en el caso de los chimilas no fue alcanzado. De esta manera, si los indígenas se habían entregado y en la práctica se había logrado su "pacificación”, su reducción y su "civilización” estaba lejos de ser un proceso afirmado, como lo veremos a continuación ${ }^{38}$.

\section{El PERIPLO y El fRACASO de los PUEblos DE Misión}

A lo largo de la documentación, constatamos que la tentativa española de fijar y de reagrupar los chimilas en pueblos de misión no logró sus objetivos, como consecuencia, por una parte, de la tendencia a la fragmentación pero no cristianizados". Otto Mass, Órdenes Religiosas de España ..., 107. 
y a la dispersión socio-política de las distintas parcialidades chimilas, en términos de los españoles, debido a su "inconstancia"; por otra parte, de las irregularidades que subsiguieron a la fundación de los pueblos impulsados por los españoles.

Desde el punto de vista de la trayectoria de las relaciones hispano-chimilas, como era de esperarse, los grandes éxitos descritos por las fuentes documentales concernientes a su pacificación serán mucho más limitados que las expectativas que ellos anunciaban. En efecto, poco tiempo después de haber sido comenzado el proceso de reducciones los misioneros capuchinos así como la administración colonial fueron confrontados a la imposibilidad de aprender y controlar por medio de los pueblos una realidad indígena móvil, fragmentaria y dispersa tal que aquella de los chimilas. $\mathrm{Al}$ respecto, las fuentes documentales presentan numerosos testimonios. De manera general, estos evocan la dificultad que experimentaba el proceso de congregaciones como consecuencia de la "inconstancia de los indios". Es decir, por su predisposición a la dispersión socio-política, así como por la alta movilidad que estimulaban prácticas tales que la agricultura itinerante, la caza, el robo de mujeres, el traslado del sitio de habitación luego de la muerte de una autoridad entre otras ${ }^{39}$. En fin, el hecho es que muy temprano los españoles descubrirían toda serie de prácticas económicas y socio-políticas entre los chimilas incongruentes con este proceso. ¿Cómo esperar que los indígenas fijaran su residencia y aceptaran las condiciones de la dominación española, si ellos no conocían ni las ciudades, ni "la vida en sociedad”, ni el gobierno, ni aún el trabajo para otros? Así lo testimoniaba el ingeniero militar Antonio de Narváez y La Torre, en 1777:

"El fijarlos [chimilas] me parece obra muy difícil y larga (...) Acostumbrados a vagar siempre no puede sufrir establecimientos constantes, a que se agrega el total estado de independencia y absoluta libertad en que hasta aquí habían vivido [el cual prefieren] al espíritu de sociedad que se les quiere infundir y les hace intolerable las más leves sujeciones que este exige. Y [tienen] una aversión invisible al trabajo que hasta ahora no han conocido, y 
vuelven naturalmente a sus montes que tienen a la vista donde con mucha menos fatiga hayan los animales, las hierbas y raíces que naturalmente producen lo que basta a sus pocas necesidades y apetitos" $"$.

En este escenario, tanto las congregaciones como el control que la Corona esperaba ejercer a través de las misiones, y la "transformación" de la realidad chimila, que debía seguir a la constitución de pueblos, afrontaron grandes dificultades. Frente a cualquier "accidente" las distintas parcialidades chimilas desertaban constantemente de los pueblos convirtiendo el proceso de reducciones en todo un periplo que difícilmente alcanzaría un punto final ${ }^{41}$.

La corta historia del pueblo de Las Pavas nos presenta un primer ejemplo de las vicisitudes que llevarían las reducciones chimilas a la ruina. Durante su fundación, este pueblo había reunido 150 indígenas, sin embargo, ante la ausencia de su misionero, que había pasado al pueblo de Garupal, estos lo desertaron ${ }^{42}$. De estos indígenas, 40 salieron al pueblo Ciénaga, donde se trató de reducirlos de nuevo, y de donde, una vez más, huyeron ${ }^{43}$. En la práctica, el pueblo de Las Pavas fue abandonado antes de haber sido terminado, y los indígenas que en él se habían intentado reunir dispersado “en las montañas". Un proceso similar puede ser observado en el caso del pueblo de Garupal, aunque las causas de la deserción fueron distintas. De acuerdo con un informe de La Sierra de 1779, la población de este pueblo, que había sido el primero "en que [los Chimilas] se acopiaron en gran número y se establecieron”, había notablemente disminuido. De los 279 indígenas censados en 1777 , solo existían 32 "al abrigo de siete familias españolas compuestas de 37 personas" ${ }^{4}$. Aunque la deserción indígena no había llegado al punto de lograr su destrucción, su configuración poblacional, en tan solo dos años se había transformado: ya no se trataba de un pueblo de misión sino de un pueblo mayoritariamente habitado por los 
vecinos "libres de todos los colores". En este caso, la deserción indígena parece haber sido promovida por las enfermedades ${ }^{45}$. Es de anotar las epidemias de viruelas que golpearon la provincia no solo había aterrorizado a los chimilas congregados, sino que además, los había casi devastado: "La epidemia de viruelas que por dos veces consecutivas ha padecido esta provincia y que asoló casi toda esta nación contribuyó a hacerlos huir a los montes y abandonar los pueblos" $"$.

Si en parte la deserción chimila de los pueblos pudo ser atribuida por los españoles tanto a su "naturaleza" como a las enfermedades, observamos, igualmente que otras razones ajenas a los indígenas, y menos contingentes que las epidemias favorecieron su abandono. Esta vez, las causas vendrán de lado español. En efecto, este proceso ya afectado por la resistencia indígena tendrá gran pena a afirmarse en un contexto regional, marcado por una fuerte dinámica de expansión territorial y económica. La documentación legada por los misioneros capuchinos, presentan claramente estas causas que propiciaron el fracaso del proceso de congregación. Desde su punto de vista, los fragmentarios logros obtenidos por ellos no podían ser tan solo atribuidos a la naturaleza "inconstante de los chimilas", sino a otros factores como la predominancia de los intereses económicos y territoriales de los españoles de la región.

Los españoles promovieron la fundación de pueblos insostenibles, lo que trajo como consecuencia que los pueblos de misión experimentaran múltiples traslados, exacerbando las huidas indígenas, y fragilizando su estabi$\operatorname{lidad}^{47}$. Los pueblos eran así erigidos en tierras inundables, poco propicias para los cultivos y malsanas por la gran presencia de mosquitos. A creer los distintos informes de los administradores locales, no existían tierras propicias para su constitución. Pero, como lo denunciaban los misioneros, el problema de su situación espacial, no se limitaba a la inexistencia de tierras adecuadas para su formación. Esta dificultad en el fondo devela-

45 [1779], AGNC, Caciques e Indios, t. 46 f. $277 \mathrm{v}$.

46 [1787] AGNC, Caciques e Indios, t. 46, f. 460r.

47 Así por ejemplo el pueblo de San Francisco de Asís (Catarina) fue trasladado tres veces, tomando nombres distintos: Ariguaní del Paso del Adelantado, Divina Pastora de la Troja (o de Potrero Grande). De la misma manera el pueblo de las Pavas fue posteriormente trasladado y tomó el nombre de Santa Cruz del Ariguaní. APCV 007132 f. 1r; 007135, f. 3. 
ba una pugna territorial en la cual primaban los intereses económicos de los vecinos de las ciudades colindantes en quienes se había distribuido su territorio $^{48}$. De esta manera, las tierras otorgadas para las fundaciones chimilas eran las peores, y su localización más que responder al deseo de los indígenas, o de tomar en cuenta las condiciones necesarias para su subsistencia, eran establecidas por las necesidades que solicitaba el desarrollo de la explotación ganadera. Esta situación es perfectamente descrita en 1778 por el visitador capuchino Antonio de Muro, quien expresaba:

"No es mi animo hacer una apología a favor de los pobres chimilas sino que sencillamente digo Vuestra a Señoría que esta mudanza tan decantada de los chimilas acaso no sucedería, si antes de fundar un pueblo se examinase a fondo si el paraje tiene buenas aguas en tiempo, si es anegadizo o no; si tiene competente terreno para las rozas, si es enfermo o mal sano, si tiene alguna plaga intolerable (...) y que es mi sentir señor el experimentarse tantas [mudanzas] es porque acaso en las fundaciones no se consulta tanto el interés de los indios como el de algunos particulares. Se consulta si acaso el paraje es apropósito o no para el paso o extracción del ganado, se consulta será útil a la inmediación de algún hato o también, principalmente, el ahorro de gastos. De aquí que viéndose los indios en un mal terreno sin cosa que los atraiga o que les ate a la libertad con nada pierden en mudarse fácilmente" 49 .

Más precisamente, en 1787, Francisco del Alcira, misionero del pueblo de Punta Gorda denunciando el "estado deplorable en que está la reducción o conquista" de los chimilas testimoniaba cómo los pueblos fundados por La Sierra habían sido establecidos con el fin de desarrollar sus propias actividades económicas. Según el misionero, el pueblo de Garupal, había sido solamente constituido por La Sierra para apropiarse de las tierras de pasto en disputa con su cuñado Tomás de Campuzano. De la misma manera, la fundación del pueblo de San Antonio le había permitido la adquisición de más tierras para la producción ganadera y la configuración de 
un punto logístico donde "los criados se aprovechan de sus bastimentos". Igualmente el pueblo de San Miguel de Punta Gorda, había sido fundado para establecer un punto de relevo de su ganado destinado a la venta en la ciudad de Cartagena ${ }^{50}$.

En otros casos los territorios de los pueblos de misión fueron completamente expropiados por medio de prácticas violentas, para la expansión de los hatos ganaderos. De esta manera lo testimoniaba, por ejemplo en 1778, el misionero del pueblo de San Francisco de Asís (Santa Martica), localizado a orillas del río de la Magdalena:

"Consiguió don Alejandro Sancho (...) que yo desamparase [las tierras] por la fuerza, como he dicho creyendo que faltándoles el pastor se descarriarían las ovejas (...) Mando el dueño de las tierras a sus esclavos que derribasen la cercar y metiesen dentro su ganado como lo hicieron (...). Lloraban los indios sin consuelo al ver la injusticia que se les hacia y querían quejarse al gobernador de Cartagena, pero por falta de medios no lo hicieron. todavía subsisten por aquella inmediación clamando cura" ${ }^{21}$.

Estas acciones no eran solo producto de la iniciativa de los vecinos españoles por apropiarse de las mejores tierras sino que ellas, asímismo, podían contar con el aval de autoridades administrativas y eclesiásticas locales. De acuerdo con el testimonio del misionero de San Francisco, él había sido obligado por el obispo de Santa Marta y Agustín de la Sierra a dejar el pueblo y trasladarse al de San Antonio, bajo la presión de la supresión del sínodo ${ }^{52}$. Para la administración colonial y eclesiástica, la prioridad no era mantener un pueblo estable sino economizar los gastos del proceso de reducción, en este caso, reagrupando los chimilas residentes en Santa Martica en el pueblo de Punta Gorda, para evitar el pago del sínodo ${ }^{53}$. En contrapartida se dejaban las tierras "civilizadas" por los indios, libres a los vecinos españoles.

50 [1787] AGNC, Caciques e Indios t. 46, f. 346v y 436r.

53 [1787] AGNC, Caciques e Indios, t. 46, f. 463r. 
A través de los distintos testimonios misioneros podemos observar que dentro de un esquema de dominación indígena totalmente distinto a aquel fundado en la explotación de la mano de obra indígena, como la encomienda, la pacificación chimila, igualmente, había permitido el enriquecimiento de sus promotores y su ascenso social ${ }^{54}$. Si creemos sus denuncias, el caso del capitán pacificador es bastante revelador. La Sierra había participado en este proceso y asumido parte de sus gastos ante la administración colonial, solo por librarse de una pena de destierro de 40 leguas a la que había sido juzgado. Su nombramiento como capitán de conquista no solo le había permitido la adquisición de tierras, sino además de títulos, como aquel de Maestre de Campo de las Milicias Urbanas de la Provincia de Santa Marta en $1780^{55}$.

La pacificación de los chimilas se convertía entonces en útil esgrimida constantemente por sus promotores como por los vecinos españoles para su beneficio económico. Pocos años antes en 1776 La Sierra, por ejemplo, había solicitado ante la Real Audiencia el usufructo exclusivo por parte de los vecinos de la provincia de los frutos de las montañas de la habitación chimila, madera, resinas y tierras de pasto para el ganado como recompensa: "pues que con tanto amor y voluntad han contribuido y concurren los vecinos de esta provincia con sus caudales y personas a la conquista y reducción de los nominados indios chimilas" ${ }^{56}$. Este tipo de disposiciones abrieron el camino para que el territorio chimila fuera apropiado por los españoles. Si bien, la información sobre la utilización de estas tierras es casi nula, al parecer fueron destinadas principalmente a la ganadería ${ }^{57}$. Pues, de acuerdo con informes españoles las tierras chimilas eran propicias naturalmente para el desarrollo de esta actividad ${ }^{58}$.

54 [1787] AGNC, Caciques e Indios t. 46, f. 436 r y v.

55 [1780] AGI, Santa Fe 59, No. 18/2.

56 [1776] AGNC, Empleado Públicos, t. 13, f. 728r.

57 Adelaida Sourdis, "Estructura de la ganadería en el Caribe colombiano", Huellas, No. 47-48, (1996): $38-48$.

58 En 1767, Tomás de Campuzano en su informe sobre las ventajas que conllevaba la construcción del camino de la ciudad de Valencia de Jesús a Santa Marta proponía: "Que sin embargo, la dilatada extensión de la referida montaña [la Sierra Nevada] ofrece en su latitud, dilatados parajes con abundantes pastos para ganados vacunos y caballares, principalmente los terrenos de Ariguaní y San Sebastián (...) que todo el terreno es más fresco que cálido, por lo mismo que este terreno se funda (está) a espaldas de la Sierra, en donde los ganados que se han visto cimarrones se crían de conside- 
Todas estas maniobras de los españoles locales, para los capuchinos, eran la fuente del fracaso del proceso de reducción chimila ${ }^{59}$. Los numerosos traslados de los pueblos y de los misioneros no contribuían a la consolidación de las misiones, ya agraviadas por la tendencia a la dispersión indígena y por su resistencia a configurar núcleos poblacionales concentrados. Cada traslado de un misionero o de un pueblo propiciaba una ocasión para que los chimilas abandonaran los pueblos de reducción. Así, una nueva campaña de "recolección de indios" y de fundación de pueblos comenzaba. Los pueblos eran fundados, abandonados y luego refundados en otro sitio con los indios de las anteriores poblaciones.

Otro ejemplo de esta situación lo proporciona el caso del pueblo de La Concepción de Venero fundado en 1781 en cercanías de la ciudad de Mompox $^{60}$. De acuerdo con un informe de su misionero Bartolomé de Vinaroz de 1787, los indígenas que habían sido congregados en él eran los mismos residentes del pueblo de Garupal, que luego había pasado al pueblo de Catarina, después al de Divina Pastora, y finalmente al de Venero. En fin, se trataba de la misma población, congregada en una nueva fundación y en lugares diferentes: "En todas estas fundaciones de unos mismos indios mediaron fatigas y quebrantos de los vecinos libres e inmediatos a las fundaciones, costos y quebrantos de los pobres misioneros" ${ }^{\prime \prime}$.

rable tamaño y grosura (...)" AGNC, Mejoras Materiales, t. 9, f. 294r. Es necesario mencionar que no solo los españoles tuvieron acceso a las tierras chimilas otras poblaciones mestizas reclamaron su derecho a estas como gratificación a su participación en las distintas entradas realizadas para su reducción. Hugues Rafael Sánchez Mejía, "De esclavos a campesinos, de la "roza" al mercado: tierra y producción agropecuaria de los "libres de todos los colores" en la gobernación de Santa Marta (1740-1810)", Historia Crítica No. 43 (2011): 135.

59 Para el caso de los pueblos de Santa Martica, Catarina, trasladado a Ariguaní, y el de Las Pavas el visitador Muro denunciaba: “(...) Santa Martica fue el primer pueblo a intentar mutación los españoles a los chimilas (...) estos estaban contentos con su fundación (...) pero los españoles por el amor de un solo particular, esto es para que un solo particular apaciente sus vacas se priva a los pobres indios de un buen terreno, al Rey de un pueblo, al pueblo de una gran conveniencia y a Dios de tantas almas". "Y hablemos claro, como habían de durar los Chimilas en el sitio de Catarina si era un paraje tan anegadizo que solo les daba paso para salir nadando (...) y como habían de preservar en el sitio o paraje del Ariguaní si estaban padeciendo el mismo perjuicio. Señor que dejaron (dicen) el pueblo de Las Pavas, es verdad. Pero porque se ha de atribuir a la inconstancia de los indios. Más acertado sería si se atribuyese a otra cosa. Este paraje es árido de suerte que en verano no tiene agua sino a costa de gran trabajo" [1779] APCV 007132/17 f. 5v y 6r.

60 [1787] AGNC, Caciques e Indios, t. 46, f. 382r.

61 [1787] AGNC, Caciques e Indios, t. 46, f. 477r. 
Los censos efectuados durante este periodo (ver tabla No. 1), aunque incompletos, ilustran la inestabilidad de los pueblos de reducción chimilas descrita por el misionero Vinaroz. Para 1786, de los siete pueblos chimilas fundados (Garupal, Divina Pastora del Ariguaní, San Francisco de Asís, Las Pavas, Venero, San Antonio y San Miguel de Punta Gorda) tan solo existían tres: Punta Gorda, San Antonio y Venero. Además, aun si los pueblos eran pequeños como podemos observarlo, la baja demográfica luego de su fundación era dramática, según de La Sierra, desde el inicio del proceso de congregaciones el $70 \%$ de la población chimila había desaparecido, entre las fugas y las enfermedades ${ }^{62}$.

\section{Tabla 1}

Población de los pueblos chimilas al final del siglo XVIII

\begin{tabular}{|l|l|l|l|l|}
\hline \multicolumn{1}{|c|}{ Pueblo } & \multicolumn{1}{|c|}{1777} & \multicolumn{1}{c|}{1785} & \multicolumn{1}{c|}{1787} & \multicolumn{1}{c|}{1788} \\
\hline San Antonio del Ariguaní & 297 & & & 82 \\
\hline Jesús de Garupal & 57 & Abandonado & & \\
\hline $\begin{array}{l}\text { San Miguel de Punta Gor- } \\
\text { da }\end{array}$ & 68 & & 56 & 50 \\
\hline Catarina & 83 & Abandonado & & \\
\hline Las Pavas & 0 & Abandonado & & \\
\hline Divina Pastora & Abandonado & & & \\
\hline San Francisco de Asís & Abandonado & & & \\
\hline Venero & & 108 & 58 & 23 \\
\hline
\end{tabular}

Fuentes: APCV, 007135/3, y Hermes Tovar, "Censo de las misiones de los capuchinos en las provincias de Santa Marta y Rio Hacha" en: Convocatoria al poder del número: censos y estadísticas de la Nueva Granada, 1750-1830 (Bogotá: Archivo General de la Nación, 1994), 522-526.

Ahora bien, podemos preguntarnos: si ¿en esta dinámica de abandono y de sucesivas refundaciones no podemos leer, así mismo, una estrategia chimila para prolongar un modo de vida nómada y una nueva forma de resistencia? Los distintos testimonios documentales que hemos presentado propondrían que sí. Si los chimilas habían depuesto las armas, en cierta medida, ellos no se habían rendido del todo ante la Corona españolos que habitaban más de mil personas, solo existen en el día los tres últimos (...) [con] trescientas seis almas $(. .$.$) cuya baja consiste de los muchos que murieron de la última peste de viruelas y otros$ que andan fugitivos de sus reducciones" [1786] AGNC, Caciques e Indios, t. 46, f. 484r. 
la, y, menos aún compartían las disposiciones de la "vida en policía" que imponía vivir bajo las condiciones de la dominación española. En este sentido, los objetivos de dispositivos como las misiones fueron logrados tan solo parcialmente. Pues, si los pueblos de misión eran fundados tanto la resistencia puesta en marcha por los chimila a través de las evasiones y en general sus prácticas sociales, comprometían su estabilidad. En consecuencia, las metas que de ellos se desprendían, tales que la transformación y la civilización de la sociedad indígena estaban destinadas al fracaso. De esta manera lo denunciaba el capitán La Sierra, en 1787, haciendo referencia al incidente entre los indios y los misioneros que había ocasionado la deserción del pueblo de Venero:

"cuyos accidentes debieras si fueran racionales impulsarle a comprender la religión y dogmas católicos, pero como su carácter es variable e inconstante y de barbará crianza, no les permite conocer su bien espiritual y consiguiente vasallaje al soberano. Es la causa por la que no se puede de golpe proceder al apremio, sino con medios suaves para con paciencia sobrellevarlos. Sin extraña, por lo mismo, lo que la experiencia ha enseñado (...) He procedido a esta reducción, como tan importante al servicio de ambas majestades, y no he podido lograr su subsistencia"63.

Frente a la dinámica impuesta por los indígenas al proceso de congregaciones la administración colonial no poseía mayores opciones, como el mismo La Sierra lo proponía: "sin otra esperanza que el continuar las frecuentes tareas que es el recogerlos en sus deserciones y agregarlos a sus respectivas doctrinas" ${ }^{64}$. Para los misioneros capuchinos, preocupados por consolidar por lo menos los pueblos, el proceso de pacificación chimila había sido un desastre y él debía ser de nuevo entamado bajo otra perspectiva. Sin embargo, otra sería la visión de la administración colonial cuya posición es expresada, a lo largo de un informe presentado ante el Rey en

63 AGNC, [1786] Caciques e Indios, t. 46, f. 383r.

64 AGNC, 1786] Caciques e Indios, t. 46, f. 383r. Es necesario mencionar que estas dificultades en el proceso de congregación llevado a cabo por los capuchinos entre los chimilas fueron evidenciadas entre otros pueblos de la región también a cargo de los capuchinos, como por ejemplo, entre los Wayúu. José Polo Acuña, “Contrabando y pacificación...”, 105. 
1787, por el entonces Teniente de Gobernación de Cartagena, Antonio de Narváez. Narváez, quien proponía no solo que los capuchinos confundían los procesos de pacificación y de reducción en pueblos, sino que además, sin justificación, desmeritaban los logros del capitán pacificador Agustín de la Sierra ${ }^{65}$. Para Narváez, las dificultades de este proceso no estaban fundadas en las irregularidades que habían sido evidenciadas a lo largo de la dinámica fundacional, sino en "la crianza bárbara, preocupaciones y carácter de estos indios, las circunstancias del país y los poco medios y arbitrios que ha habido para ellos"66. Es decir, además de la reiterada "naturaleza de los indios", las causas del fracaso de este proceso eran las condiciones físicas de la región y la falta de medios económicos para proyectar un verdadero proceso de reducción. Parece, en realidad, que para finales del siglo XVIII después de tantos años de ensayos y gastos de someter a los chimilas, la administración colonial había en parte renunciado o postergado esta tarea, pues estos ya no propiciaban mayores problemas. Así, lo descubrimos, por ejemplo, en su respuesta frente a la proposición de trasladar los chimilas a la gobernación de Cartagena:

"y que me parece menos inconveniente que este, el que los indios anduviesen vagantes, respecto a que se lograba daño alguno que es lo principal, hasta que con el tiempo y la paciencia y el trabajo se fueran radicando. No habiendo accedido el Excelentísimo Señor [Virrey] Flores a estas proposiciones, se sirvió por un decreto (...) de mandar que se procediese a las reducciones de estos indios con mucho tiento y madurez sobrellevando su inconstancia hasta que las urgencias precisas del Reino permitiesen más eficaces providencias" 67 .

El testimonio de Narváez resume lo que será la continuación de las políticas de reducción a finales del siglo XVIII. En gran parte, estas se caracterizarán por cierto descuido por parte de la administración colonial. Las

65 "y dicen que son entusiasmo de don Agustín de la Sierra que no hay tan pacificación, que esta tan sentada y sólidamente establecida que un hombre solo puede ya caminar y a travesar, y en efecto camina y atraviesa cada día toda la provincia sin riesgo alguno y no se ha vuelto a ver un español, ni herido por estos indios" [1787] AGNC, Caciques e Indios t. 46, f. 459r.

66 [1787] AGNC, Caciques e Indios t. 46, f. 460r.

67 AGNC, Caciques e Indios t. 46 f. 466r. 
acciones conducidas para la reducción chimila fueron restringidas a la realización de algunas expediciones, así como la configuración de otros pueblos, que para finales del siglo XVIII ya no estarán bajo el mando de los capuchinos sino clerigos seculares. Al igual que los pueblos precedentes, ellas tendrán dificultades para subsistir tanto por las huidas de los indios, pero también por la falta de ministros eclesiásticos para asistirlas. Durante la décadas de los 90, por ejemplo, dos de los pueblos chimilas que apenas subsistían pocos años antes (Punta Gorda, y Venero) fueron completamente abandonados por los chimilas ${ }^{68}$. Quienes, además, reiniciaron algunas incursiones aisladas contra los españoles ${ }^{69}$. En este contexto La Sierra realizará las últimas expediciones, que permitieron congregar algunos de los indios extraídos de las montañas al pueblo de San Antonio, y posteriormente a un nuevo pueblo denominado San Antonio de Guayacanes que reuniría toda la población chimila reducida ${ }^{70}$.

Para 1801, ya muerto el capitán pacificador, como lo muestra un informe de los vecinos de Valencia de Jesús sobre el estado de las reducciones chimilas, los pueblos sobrevivientes apenas subsistían con algunos indígenas. La población del pueblo de los Guayacanes que en 1796 sobrevivía con más de 100 indígenas, había sido en gran parte desertada. El testimonio de Juan Ávila uno de los vecinos de Valencia de Jesús dibuja el estado catastrófico de las congregaciones chimilas a inicios del siglo XIX.

"En otros dos parajes de las inmediaciones de las montañas, nombrados las Bodegas y Río Frío había también unos cortos indios que también se reunieron pidiendo cura, que les fue puesto, solo en calidad de interino y aunque se les retiró, todavía subsisten congregados en dichos parajes (...) este es el estado que en aquella época tuvo la reducción chimila porque malogrado (...) todo lo demás (los indios y no pocos que antes llegaron a verse

68 [1791] AGNC, Curas y Obispos, t. 11, f. 317v, f. 325, [1792], Poblaciones Varias, t. 36, f. 995r.

69 [1797] AGNC, Caciques e Indios t. 46, f. 756r.

70 [1797] AGNC, Caciques e Indios t. 46, f. 756r. En 1790 podemos observar la constitución de otro pueblo llamado San Luis de Guaquiri o Las Pailas, con una población aproximada de 50 indígenas todavía en manos de los capuchinos. Sin embargo, parece que dicha fundación no pervivió, probablemente como consecuencia de un litigio de tierras con un vecino español. [1790], AGNC, Caciques e Indios t. 46, f. $624 \mathrm{r}$ y ss. 
bajo campana se hallaban como hasta a hoy lo están, vagando en el centro de la montaña (...) el pueblo de Guayacanes, existe también reducido sólo a siete familias, y con igual falta de cura, porque él que últimamente le fue nombrado resiste asistirlo por falta de Sínodo"71.

Para inicios del siglo XIX, la administración colonial había abandonado en gran parte el proceso de reducción chimila. En el único pueblo que subsistía ni siquiera aseguraba la presencia de los eclesiásticos. En realidad, luego de las últimas expediciones realizadas en la décadas de los 90, las relaciones entre los chimilas reducidos y los españoles se limitaron a la presencia intermitente de sacerdotes españoles para su adoctrinamiento, $y$, principalmente a una serie de dones que eran ofrecidos cuando los indígenas salían a las ciudades españolas. En cierta medida, "la paz" de los establecimientos españoles y el frágil control de los indios que habían logrado las misiones se prolongaba a través de la instauración de una nueva relación de dependencia de aquellos insumos que los españoles habían empleado en otro tiempo para atraer los indios a la "vida política": "Que en solicitud de esto se trasladan muchas veces a esta ciudad y a cada uno se les daba vestidos, hachas y machetes con que se volvían muy contentos a sus pueblos. De modo que encontrando a una sola persona en su tránsito no llegaban nunca a ofenderse" 72 .

Pero, a pesar de las relaciones "pacíficas" descritas, simultáneamente, los chimilas continuaron realizando ataques armados contra los asentamientos españoles. Estas acciones una vez más trataron de ser atenuadas a través de nuevas entradas a manos de capitanes de conquista y la fundación de nuevos pueblos, cuyo esfuerzo al igual que las misiones no ocasionó un resultado definitivo en términos de la reducción indígena ${ }^{73}$. De esta manera, en la primera década del siglo XIX, las acciones de los chimila que aún subsistían sin "reducir" se enmarcaban en un mundo móvil y ambiguo entre el conflicto y la negociación, en parte resultado de la apropiación indígena de nuevas ideas y formas de relación con el mundo español que

73 Edgar Rey Sinning, Poblamiento y resistencia..., 234-237. 
habían sido instaurados por las entradas mixtas y las misiones, como el intercambio de insumos, la formación de pueblos y la presencia de unos religiosos $^{74}$. En este sentido, si las misiones habían sido todo un fracaso, ellas habían delineado relaciones de negociación que perduraron hasta los albores de la época republicana.

Para este momento, por lo demás, la realidad chimila no era una realidad homogénea, pues las distintas fracciones indígenas no actuaron en bloque, así por ejemplo, algunos de sus miembros se perdieron en la trama del mestizaje promovido por la extracción fraccionada de sus miembros y el proceso de consolidación de pueblos inacabados, mientras que otros permanecieron ocultos en las "montañas de su habitación” manteniendo frágiles contactos con el mundo español, y después republicano. Entre los miembros de estas parcialidades que permanecieron ocultas, podemos reconocer los ancestros de los actuales chimila, los cuales pudieron sobrevivir, a pesar de los vaticinios de su extinción dado por los viajeros y antropólogos en la primera mitad del siglo XX, y de las nuevas dinámicas poblacionales que finalmente alcanzaron sus sitios de habitación durante este siglo $^{75}$. En estas nuevas dinámicas promovidas por la explotación ganadera y la extracción de recursos maderables los miembros chimilas fueron expropiados de los pocos reductos territoriales que habían conservado e, igualmente, integrados a la sociedad local republicana ${ }^{76}$. Frente a esta nueva situación los chimilas respondieron con el mimetismo y el ocultamiento de sus tradiciones, hasta finales del siglo pasado, cuando condiciones más favorables les permitieron develar públicamente su identidad étnica ${ }^{77}$.

\section{Consideraciones Finales}

Dos grandes conclusiones surgen del trabajo realizado. La primera concierne los verdaderos objetivos que encubrieron la pacificación chimila, en un contexto temporal tardío, y en una región en la cual la colonización es-

74 AGNC, Caciques e Indios t. 46, f. 641r.

75 Gustaf Bolinder, "Los Últimos Indígenas Chimilas” Boletín del Museo del Oro No. 18 (1987): 10-27; Gerardo Reichel-Dolmatoff, Los indios chimilas: etnografía, mitología, lingüística (Bogotá: Instituto Etnológico Nacional, 1944).

76 Edgar Rey Sinning, Poblamiento y resistencia..., 276-277.

77 Marcela Quiroga Zuluaga, "Caminando íbamos viviendo" Folio No. 29 (2001): 29-38. 
pañola, a causa de la resistencia indígena, se había consolidado fuera de las formas de control y de explotación tradicionales de la población indígena. En efecto, por encima de la tan reiterada argumentación española sobre la sumisión y reducción de los chimilas se constata que las distintas acciones desarrolladas por los administradores locales a lo largo del proceso de congregación de los indígenas más que responder a un verdadero interés por realizar los fines ideales de la dominación colonial, -como la construcción de un vínculo real con la Corona, la evangelización y la "conversión de los indios"- fueron impulsadas por una dinámica de expansión territorial y económica regional, así como por los intereses personales de sus gestores, que en último término se proponía la apropiación de sus territorios.

La segunda, porta sobre los limitados resultados de este proceso como consecuencia no solo de las irregularidades del lado de los españoles, sino también de la destreza y adaptación de las estrategias indígenas frente a la dominación española. Primero por las armas, luego por prácticas como la dispersión, la alta movilidad territorial, y finalmente la evasión; los chimilas obstaculizaron cualquier tentativa estable de sumisión y de reducción proyectada por el proceso de congregaciones y las misiones. En cierta medida, "su inconstancia” desgató y truncó la acción de estos dispositivos aun antes de ser consolidados. Como consecuencia, las parcialidades indígenas refugiadas en el centro de la montaña de su habitación parecen haber quedado libres de cualquier efecto de los mecanismos de la dominación colonial. Sin embargo, a lo largo de esta prolongada confrontación contra el poder colonial los indígenas no escaparon ilesos. La disminución demográfica como causa de las enfermedades, la articulación atomizada de sus miembros a los pueblos de españoles e indígenas, y en consecuencia la desaparición de algunas parcialidades fragilizaron este pueblo, cuya única opción de supervivencia parece haber sido la evasión, la dispersión y el establecimiento de frágiles contactos con el mundo no indígena.

Desde el punto de vista de la administración regional, el balance del proceso de congregación de la población indígena a pesar de su fracaso no fue tan negativo. En efecto, los pueblos de misión chimila no lograron los grandes ideales de la dominación colonial que proponían su transformación, sin embargo, las pocas parcialidades que subsistieron fueron expulsadas de sus territorios y "controladas" dejando de ser un obstáculo 
para el mundo español. Pues, si bien es cierto que fracciones chimilas continuaron sus ataques a los asentamientos españoles hasta la primera década del siglo XIX, estos estaban lejos de poner en juego una colonización ya consolidada y su desarrollo económico, como había ocurrido en los siglos anteriores.

\section{Bibliografía}

\section{Fuentes primarias}

\section{Archivos}

Archivo General de Indias (AGI), Sevilla-España, Santafé.

Archivo General de la Nación de Colombia (AGNC) Bogotá - Colombia, Sección Colonia, Caciques e Indios, Conventos, Curas y Obispos, Empleados Públicos, Mejoras Materiales, Milicias Marina, Poblaciones Varias.

Archivo Provincial de los Capuchinos de Valencia (APCV), Valencia-España.

\section{Fuestes primarias impresas}

Antonio, Julián. La perla de América, Provincia de Santa Marta, reconocida y observada y expuesta en discursos históricos, Madrid: Editor Don Antonio de Sacha, 1787.

Colmenares, Germán. Relaciones e informes de los gobernantes de la Nueva Granada. Bogotá: Biblioteca del Banco Popular, 1989.

La Rosa, José Nicolás (de). Floresta de la Santa Iglesia Catedral de la Ciudad y Provincia de Santa Marta. Bogotá: Banco de la República, 1975. Mier y Guerra, José (de). Poblamientos en la Provincia de Santa Marta, siglo XVIII, t. 2. Bogotá: Libreros Colombianos, 1987.

Tovar, Hermes. Relaciones y Visitas a los Andes, siglo XVI, T. II, región Caribe, Bogotá: Colcultura-Instituto Colombiano de Cultura Hispánica, 1993.

\section{Fuentes secundarias citadas en el artículo}

Boccara, Guillaume. Guerre et ethnogenèses mapuche dans le Chile Colonial. París: LHarmattan, 1998. 
Bolinder, Gustaf. "Los Últimos Indígenas Chimilas”. Boletín del Museo del Oro No. 18. (1987): 10-27.

Evans-Pritchard. Les Nuer. Paris: Gallimard, 1975.

Fals Borda, Orlando. Historia doble de la Costa 1. Mompox y la Loba. Bogotá: Universidad Nacional de Colombia-Banco de la República Áncora Editores, 2002.

Herrera Ángel, Martha. Ordenar para controlar, ordenamiento espacial y control político en las llanuras del Caribe y en los Andes centrales Neogranadinos, siglo XVIII. Bogotá: Instituto Colombiano de Antropología, 2002.

Luna G., Lola. Resguardos Coloniales de Santa Marta y Cartagena, y resistencia indígena. Bogotá: Fondo de Promoción de la Cultura, 1993.

Luna, Lola. "La Nación Chimila: Un caso de resistencia indígena en la nación de Santa Marta”. En Conquista y resistencia en la historia de América, editado por Pilar García Jordán. Barcelona: Universitat de Barcelona, 1991.

Luquetta Cediel, David, y Antonio Vidal Ortega. "La vida Material del otro lado de la frontera colonial: los pueblos chimilas en la segunda mitad del siglo XVIII", Diálogos, Revista electrónica de historia, Vol. 15, No. 1 (2014): 211-233.

Mass, Otto. Órdenes Religiosas de España y la Colonización de América. Barcelona: Fidel Giro Impresor, 1918.

Mendoza Ramos, César Augusto. "La provincia de Santa Marta: Espacio y poblamiento 1780-1810”. Amauta No. 14 (2009): 29-54.

Mörner, Magnus. Las Comunidades de indígenas y la legislación segregacionista en el Nuevo Reino de Granada. Anuario de Historia Social y de la Cultura, Vol. 1, (1963): 63-88.

Polo Acuña, José. "Contrabando y pacificación en la frontera colombo-venezolana”. América Latina en la Historia Económica No. 24 (2005): 87-130.

Quiroga Zuluaga, Marcela. "Caminando íbamos viviendo" Folio No. 29 (2001): 29-38.

Reichel-Dolmatoff, Gerardo. Datos histórico-culturales sobre las tribus de la antigua Gobernación de Santa Marta. Bogotá: Banco de la República, 1951.

Reichel-Dolmatoff, Gerardo. Los indios chimilas: etnografía, mitología, lingüística. Bogotá: Instituto Etnológico Nacional, 1944. 
Rey Sinning, Edgar. Poblamiento y resistencia: los chimila frente al proceso de ocupación de su territorio. Santa Marta: Gobernación del Magdalena - Edición al cuidado de Conexión Cultural Editores, 2012.

Sánchez Mejía, Hugues Rafael. "Composición, mercedes de tierras realengas y expansión ganadera en una zona de frontera de la gobernación de Santa Marta: Valledupar (1700-1810)". ACHSC Vol. 39 No. 1 (2012): 81-117.

Sánchez Mejía, Hugues Rafael. "De esclavos a campesinos, de la "roza” al mercado: tierra y producción agropecuaria de los "libres de todos los colores" en la gobernación de Santa Marta (1740-1810)". Historia Crítica No. 43 (2011): 130-155.

Sourdis, Adelaida. "Estructura de la ganadería en el Caribe colombiano", Huellas, Nos. 47-48, (1996): 38-48.

Tovar, Hermes. Convocatoria al poder del número: censos y estadísticas de la Nueva Granada, 1750-1830. Bogotá: Archivo General de la Nación, 1994.

Uribe, Carlos Alberto. "Un antropólogo sueco en Colombia, Gustaf Bolinder”. Revista del Banco de la República, No. 18 (1987): 3-9.

Uribe, Carlos Alberto. "La rebelión chimila en la provincia de Santa Marta Nuevo reino de Granada en el siglo XVIII". Estudios Andinos No. 13 (1977): 163-165.

Wilde, Guillermo. Religión y poder entre las misiones de guaraníes. Buenos Aires: Editorial Sb, 2009.

Para citar este artículo: Quiroga Zuluaga, Marcela. "Entre la inconstancia y la incuria: La experiencia fallida de los pueblos de misión chimilas a finales del siglo XVIII, en la llanuras del Caribe", Historia Caribe Vol. X No. 26 (Enero-Junio 2015): 257-289. DOI: http://dx.doi.org/10.15648/ hc.26.2015.9 